\title{
Eco-Friendly Asphalt Approach for the Development of Sustainable Roads
}

\author{
Soleen Jaber Ahmad Al-Hasan ${ }^{1}$, R. Balamuralikrishnan ${ }^{1 *} \oplus$, Motasem Altarawneh ${ }^{1}$ \\ ${ }^{1}$ Department of Civil and Environmental Engineering, College of Engineering, National University of Science and Technology, PO Box:2322, \\ CPO Seeb 111, Muscat, Sultanate of Oman
}

Received 05 June 2020; Revised 10 August 2020; Accepted 16 August 2020; Published 01 September 2020

\begin{abstract}
Currently, various types of recyclable materials are used in civil engineering applications. One of the future challenges in the civil engineering field is sustainability and the bulk utilization of waste materials without affecting the performance of the product related to the civil engineering field. The presence of bulk amounts of disposed and demolished materials, including aggregates and undecomposed recycled polymers, can be recycled. The main aim of reducing environmental impact and also reduction in the cost. Present research focusing on recycled polymers as partial replacement of bitumen in addition to recycled coarse aggregate in different percentages are investigated for its feasibility used in road construction. To achieve the objectives of the current research, six batches of bituminous samples were prepared, and each case considered three samples for repeatability. The first batch is considered as a control sample without adding Recycled Coarse Aggregates (RCA) and recycled polymer. The second batch consists of a $15 \%$ partial replacement of bitumen using polymer without recycled aggregate. Remaining batches 3 to 6 were 15\% partial replacement of bitumen with polymer and partial replacement of coarse aggregates using recycled coarse aggregate say $25 \%, 50 \%, 75 \%$, and $100 \%$. Each batch was tested by reliable and standard tests in order to determine the most efficient mix (batch). The testing methods followed in this investigation are the sieve analysis test, impact test, Los Angeles test, penetration test, and marshal test. The results of a sieve analysis test showed that the fineness modulus value for RCA equals to $4 \%$ with a uniform graded graph. The specific gravity test results showed that RCA specific gravity is 2.61, which indicates that RCA is considered as coarse grained soils. Moreover, the impact test for RCA equals $9.3 \%$. In addition, the result for Los Angeles for RCA value is $19.07 \%$, and comparing it with the standard, it should be less than $30 \%$ to be suitable for road construction. Furthermore, penetration test results of $15 \%$ partial replacement of bitumen using polymer showed that the average value equals $58 \mathrm{~mm}$ compared to $63.7 \mathrm{~mm}$ for bitumen without polymer. Finally, the result obtained from the Marshall Stability test showed that batch 5 partial replacement of bitumen $15 \%$ using polymer and the partially replaced normal coarse aggregate $75 \%$ with RCA gives better results in all aspects. A fruitful conclusion from this study is to follow the approach of utilizing recycled coarse aggregate along with recycled polymers in road construction.
\end{abstract}

Keywords: Normal Coarse Aggregate; Recycled Coarse Aggregate; Bitumen; Polymer; Marshall Stability Test.

\section{Introduction}

One of the future challenges civil engineers face is the sustainability and best utilization of huge amounts of waste materials available without affecting the performance of the product. Countries need to focus on the challenge resulting from the presence of huge amounts of disposed and demolished materials related to their impact on humans

* Corresponding author: balamuralikrishnan@nu.edu.om

doi) http://dx.doi.org/10. 28991/HEF-2020-01-03-01

$>$ This is an open access article under the CC-BY license (https://creativecommons.org/licenses/by/4.0/).

(C) Authors retain all copyrights. 
and the environment. The solution to such challenges is the utilization of recycling. The huge amounts of disposed materials need to be recycled with the aim of reducing the negative impact on both the environment and cost. This could be of vital importance during rehabilitation and maintenance of roads and buildings. The fact of limited natural resources encourages researchers to move in this direction of using recycled aggregates and polymers. The planned work is taking the idea of recycling of aggregate and polymers into consideration, which will consequently reduce the amount of recycled material and lead to a reduction in cost for the whole produced product.

For the utilization of disposed and demolished polymers and aggregates, the planned work is to be conducted with $8 \%$ of polymer (Wax Polymer Waste) in addition to the utilization of different reduction percentages of new recycled aggregates with the percentages of $25,50,75$, and $100 \%$ considering replacement percentages of recycled new aggregates. The utilization of polymer and aggregate recycled waste in road construction has the effect of improving the road performance compared to traditional roads. This can be noticed in terms of the resulting improved values of durability, stability, strength, and life of the road. The day-to-day rise of various types of waste that are non-biodegradable is increasing severely, which in turn is a threat to life. Plastic waste is highly impossible to get decomposed on the earth's surface. Both these problems can be solved by providing a solution involving using plastic waste in flexible pavement construction [1]. The advantages of this approach to integrating RCA in asphalt lead to additional advantages, including decreasing the energy consumption used in producing new aggregates, creating more chances for areas with low aggregate natural resources, reducing the negative effect on the environment by reducing harmful gas emissions, and consequently minimizing the cost of projects. The aim of this project is to evaluate the performance of eco-friendly asphalt towards the development of sustainable roads. The project has been designed in a way to investigate the effect of incorporating polymer and recycled new aggregate on the physical properties of hot mixed asphalt using bitumen grade of 60-70. The different combinations previously mentioned are planned to be tested for mechanical and physical properties. These tests would decide the feasibility of the percentages against the tested properties [2].

\subsection{Benefits of Recycled Aggregates and Polymers in Eco Road}

The polymer material has a dangerous effect on the environment because of its long stay on the earth's surface. It can live for 4500 years and cause health hazards. The only solution to such a challenge is to expose such materials to degradation processes and select suitable applications for polymers where the polymers can be integrated. Researchers found the recycling of polymers is a suitable solution and the utilization of them in eco-roads will help in improving the properties. This is done by using Bitumen 60/70 with suitable ratios of cement aggregates. The green road concept inspires optimum utilization of local resources as one of the important indicators of sustainable development. The form of re-utilization of materials is economic and environmentally friendly [3].

As stated by researchers, the challenge of accumulation of polymer materials was tackled by Ghana in the year 2000. The approach followed involved the integration of polymer materials with aggregate in eco road construction by utilizing dry and wet processes where the mixed polymers with aggregate are added to bitumen [4]. The idea of integrating polymers within road construction was expanded to different countries, as stated by the researchers. The polymers, in addition to aggregates, are used in eco-road construction in India, the UK, the Netherlands, Ghana, Ethiopia and South Africa. As a result of this application, it was found that the durability of roads and the pavement performance were improved [5]. Due to poor elastic properties and adhesion, bitumen is a viscoelastic material which is not able to perform satisfactorily in asphalt pavement to control rutting deformation and cracking under adverse climatic conditions and heavy traffic loads. To improve the properties of asphalt binder, the binder needs to be altered with general types of additives to enhance the performance of bitumen [6].

The recycling of concrete and its utilization in roads attracts all researchers, especially with the limited amount of concrete production in a year of 6 billion tons. In Europe, the production of concrete reached a maximum of 180 million tons per year, which is not meeting the demand. This forced European countries to move towards using recycled polymers as a substitute for concrete waste in the road construction industry. This was considered as the best solution for compensating the increasing demand for concrete, in addition to protecting the environment from the harmful effects of concrete accumulation [7]. The consumption of large quantities in the USA for road construction reached a cost of 150 billion dollars at an amount of 320 million tons. This puts pressure on the limited amount of natural resources from this material and leads researchers to follow the approach of recycling to reduce the cost and limitations related to the availability of such natural resources. The same approach was followed in Arab countries where the demand for natural concrete was irregular and increased dramatically with time [8]. Feasibility of using recycled polymer waste and aggregates in road construction the utilization of polymers varies from one country to another. Nowadays, traditional road materials, procedures, and techniques are expected to deliver a minimum performance, but unexpected new challenges have a negative impact, reducing their lifetime. In addition, each kilometre of road requires a large amount of materials and energy for its construction, maintenance, and rehabilitation, which are not viable according to new environmental patterns. Hence, the search for more cost-effective and ecofriendly practices in the road sector represents a priority for the industry [9]. 
A plethora of modern-day expectations and needs rely on road pavement networks. As such, they must provide efficient and safe transportation, economic and environmental sustainability, and convenient modes of travel that are both accessible and reliable. Sustainable developments refer to the ethical and conscious consumption of natural resources to curb global warming and air contamination [10]. Overcomes the challenge of accumulation of such non biodegradable materials by using it in road construction by combining this waste with aggregate, PCA, and bitumen mixtures. The percentage of recycled polymer used in roads in India in 2015 was found to reach 60\% [11]. The integration of polymers in road construction with hot and humid climate is found to be feasible and helps in rescuing the environment with the hazards resulting from the accumulation of this used huge quantities of polymers [12]. The need for more roads in Ghana due to the increased population requires more maintenance to the existence roads that have low durability factor attract researchers' attention to search for solutions to such a challenge. It was found that additives to road construction such as polymers, rubber and other crumb rubbers have the effect of improving the properties and durability of roads. The performance was noticed to be improved more when recycled polymers were used in bitumen concrete mixture [13]. The maintenance of roads in the USA is consuming big amounts of natural aggregates which have a limited quantity that is available in nature. In Hong Kong and similar countries, the demand on aggregate is similar to that for polymers for road construction. The utilization of demolished concrete by recycling is found to be feasible in Egypt where the estimated quantity of demolished concrete was found to reach 4 million tons resulting from demolishing high rise buildings in the year 2015. This helped in using recycled concrete in road construction in addition to using recycled clay masonry bricks for construction applications [14]. Flexible pavements failure often occurs due to excessive permanent deformation (rutting) as a result of the undesirable environmental conditions and heavy traffic under repeated wheel loads. The development of such pavements performance has been considered valuable by reinforcing asphalt mixture [15].

The preparation of recycled polymers in terms of plastic litter, used carry bags, and other plastic bottles [16]. The process of collection is followed by segregation, cleaning by de dusting, washing and at the end cutting into small pieces with sizes of $1.18 \mathrm{~mm}$. The preparation of recycled aggregates is also investigated by different researchers. Cold bitumen emulsion mixture technology has a wide range of production temperatures as it is usually manufactured at ambient temperatures under different environmental conditions without heating for both aggregates and bitumen [17].

This is done on specimens prepared by dry and wet methods. Other researchers have taken recycled aggregates and prepared samples in cubes and then proceeded with Marshal testing for hot mix asphalt. Brookfield rotational viscosity, and softening point tests are also used. The result of research here is that cost is reduced and the benefits gained are more than that since lower maintenance cost, and improved quality of pavement were achieved [18]. Researchers continue proceeding with investigation of the effect of use of recycled polymers on cost. The cost found to be decreased, in addition to increasing the life of eco roads [19]. An extensive review of cold mix asphalt in terms of emissions and energy savings due to asphalt mixture manufacturing processes used by the road pavement industry have been surveyed [20]. At present, recycled materials are frequently used in the base layers of asphalt pavements. This method is used for the shoulder of rural and urban road pavements via cold or hot-in place recycling. It involves the addition of a very small amount of additive material to the asphalts [21]. Climate change ambiguities coupled with the collapse of natural plus non-renewable resources are essential considerations that illuminate the prerequisite for inventive alterations that will advantage to a safer atmosphere prospect for everyone [22].

Sustainability is the fulfillment of human needs and technological advancement with the least possible environmental and economic costs. Transportation is the primary need of human beings and developing sustainable transportation facilities is of main concern [23]. As a closed space, the functional requirements of the tunnel pavement are very different from ordinary pavements, e.g., a higher requirement on the reduction of the pavement noise, proper light reflection to ensure safety and save tunnel lighting energy, closure of the construction process, better pollutant discharge and air purification [24]. The construction industry consumes a large number of resources and energy, in contrast to other sectors of the contemporary economy [25]. The demand for more sustainable solutions has led an ever-growing number of stakeholders to being committed to pursue the principles of sustainability in pavement management. The roads are not only an important part of a society's transportation network, but also a public asset in overall terms. Indeed, the transport of goods and people worldwide is mainly done by road infrastructures [26]. Modern pavements not only need to satisfy the mechanical performances but they also need meet the requirements of service performances in regard to security, smoothness, comfortable driving, and environmental effects according to different traffic environments [27]. The target of this study is to produce eco-friendly green material concrete using different waste materials. The literature review helps to confine the present study objectives and scope.

\subsection{Objectives}

- To investigate the effect of incorporating polymer and recycled new concrete on the physical properties of hot mixed asphalt. 
- To measure the mechanical performance of the modified hot asphalt combined with recycled new aggregate and polymer material utilizing several testing methods.

- To propose a strategy to reduce the environmental impact of waste materials including waste Polymer and recycled new aggregate.

1.3. Scope

- Improving the quality of bitumen which is considered as new approach

- To improve the road strength by utilizing waste polymers and aggregate.

- Achieve the target of having Eco-friendly roads.

\section{Experimental Investigations}

It is very important for this project to test and compare the results of normal and eco-roads. The eco-roads are utilizing the recycled aggregate in addition to adding bitumen in different percentages. The percentage of $15 \%$ (recycled polymer) in bitumen is fixed and used. The recycled aggregate is used also in different percentages $(25,50$, 75, and 100\%). The recycled aggregates can be collected from different locations of demolished buildings. The phase of progress in construction is a continuous process which is happening on a daily basis in all countries in different locations with old buildings being demolished and new buildings replacing them. This results in the presence of accumulated amounts of concrete which can be recycled. For the purpose of the current research, the recycled aggregates were collected from the tested concrete cubes (Figure 1).

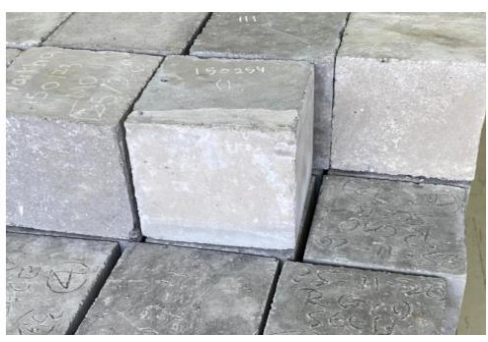

Figure 1. Concrete cubes

\subsection{Recycled Coarse Aggregate}

The crushing machines shown in Figures 2 and 3, were used to crush the demolished pieces of concrete cubes to smaller aggregate pieces to meet the standard size of normal coarse aggregate and testing the new crushed stone by sieve analysis to find the FM and compare it with the standard value of normal coarse aggregate. The sizes of the produced demolished aggregates can be controlled by rolling the wheel shown in Figures 4 and 5 .

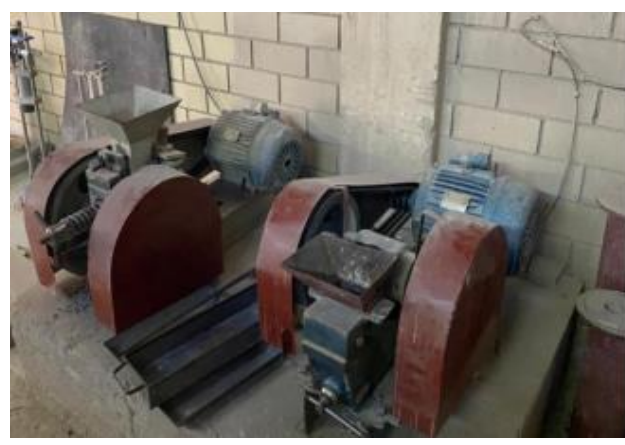

Figure 2. Crushing Machines

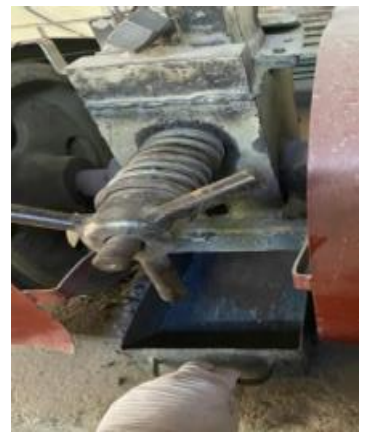

Figure 4. Crushing Machine controlling wheel

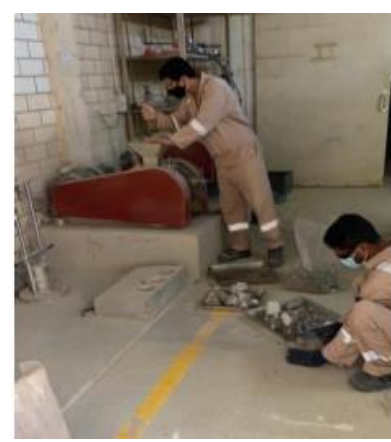

Figure 3. Putting the concrete cubes in the machine



Figure 5. Size of Aggregate 


\subsection{Bitumen}

Bitumen is one of the main materials used in this research which is known as asphalt (Figure 6). The Paving grade of bitumen used is 60/70 referred penetration value within the range of 60 to 70 at standard test conditions. It is originally formed from distillation processes of crude oil. Since it is from crude oil, it is considered as organic, that is hydrocarbon based material. There are different applications of bitumen in real life. This includes waterproofing, marine applications, connection and bonding of building materials together, and paving of roads.

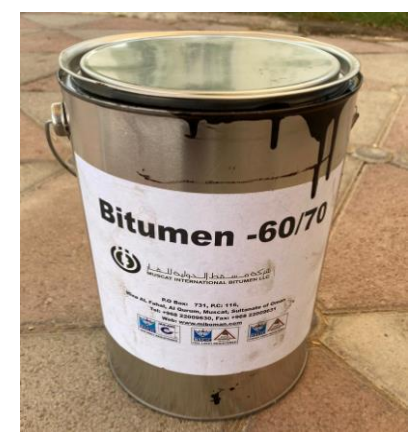

Figure 6. Bitumen (60/70)

\subsection{Polymer}

Polymers is one of the important types of materials that are used in different applications. They are produced by refinery processes and can be classified as thermoplastics, and thermosetting types of polymers. The polymers from its name has two terms: poly and "mer". The poly is referring to repetition of the smaller unit (mer) and according to type of polymer there are many applications linked to each classification of polymers (Figure 7).

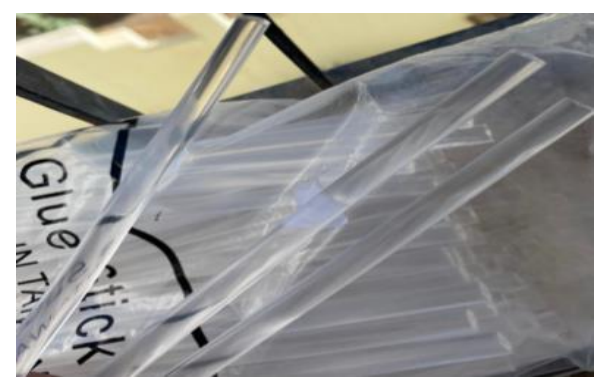

Figure 7. Polymers

\subsection{Penetration Test without Polymer}

The penetration test is used for testing the penetration of a given material. As measured value of penetration increased, consistency is increased. This test is commonly used for solid and semi bitumen types of materials (Figures 8 to 10$)$.

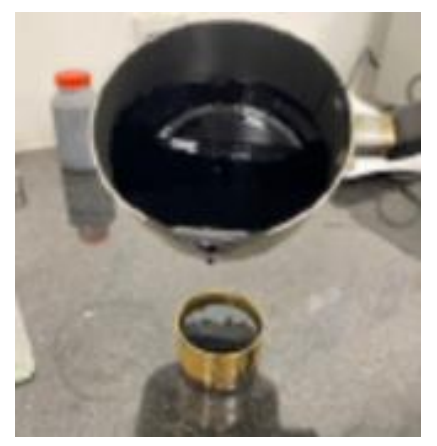

Figure 8. Preparing the Bitumen Sample



Figure 9. Placing the sample (without polymer) in the water bath

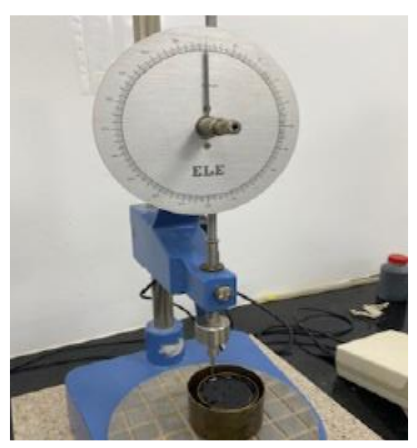

Figure 10. Putting the Sample (without Polymer) in the penetration apparatus

\subsection{Penetration Test with $15 \%$ of polymer}

The penetration test with $15 \%$ polymer is used for testing the penetration of a given material. As measured value of penetration increased, consistency is increased (Figures 11 to 14). 


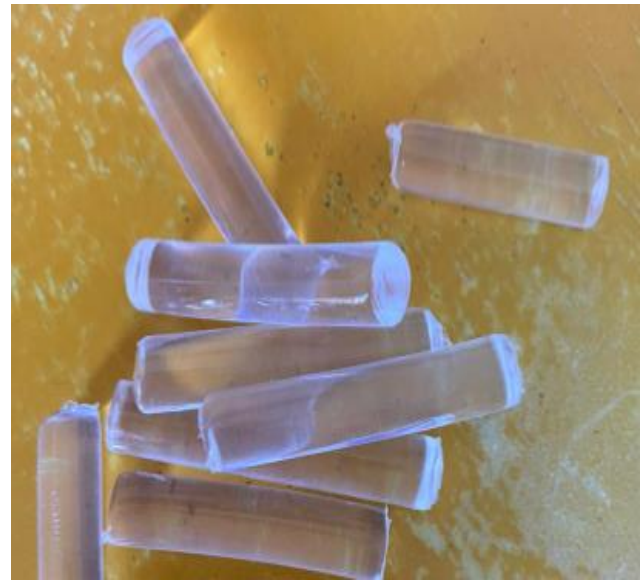

Figure 11. Cutting the polymers to small pieces

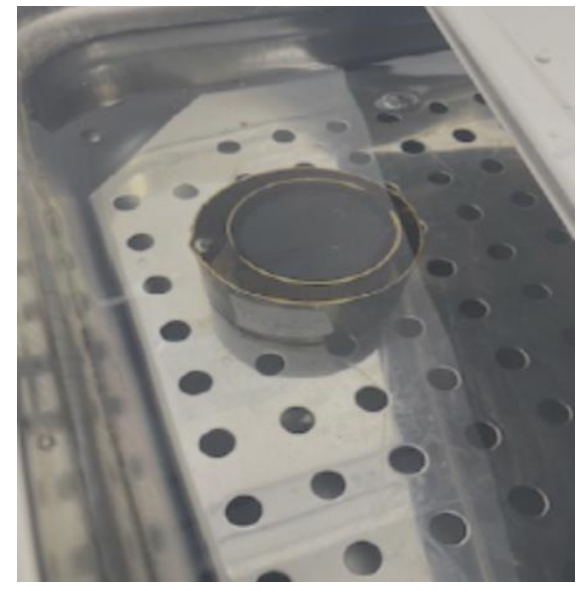

Figure 13. Putting the sample (with $15 \%$ polymer) in water path

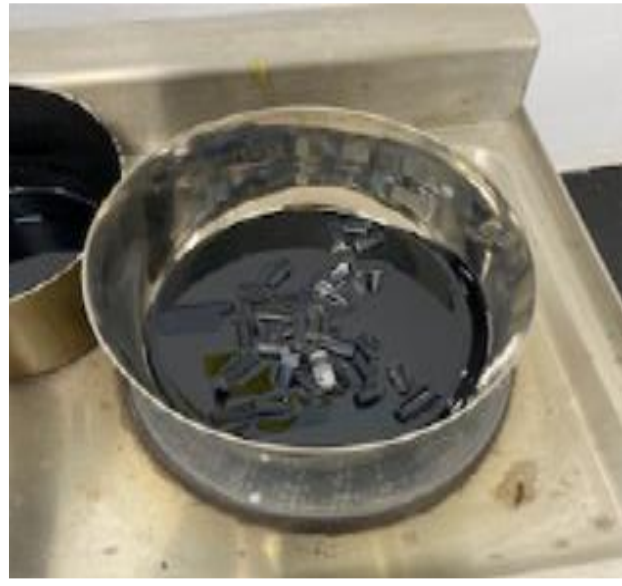

Figure 12. Heating the polymers with the heated bitumen

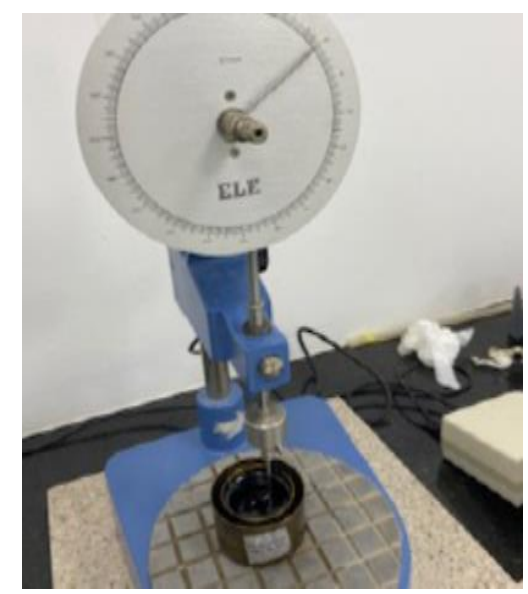

Figure 14. Putting the Sample (with $15 \%$ Polymer) in the penetration apparatus

\subsection{Marshall Stability Test}

The strength and flexibility was tested using "Marshal Stability Test". The voids within the structure of bitumen mixtures were tested using marshal test. Table 1 shows all percentages of Bitumen, polymers, recycled aggregates and fillers were tested by marshal test [28-32].

Table 1. Marshal Stability \% content

\begin{tabular}{ccccccc}
\hline Batch & Number of Samples & Bitumen \% & Polymer \% & Aggregate \% & Recycled Aggregate \% & Filler\% \\
\hline B1 & 3 & 4 & 0 & 96 & 0 & 4.5 \\
B2 & 3 & 4 & 15 & 96 & 0 & 4.5 \\
B3 & 3 & 4 & 15 & 96 & 25 & 4.5 \\
B4 & 3 & 4 & 15 & 96 & 50 & 4.5 \\
B5 & 3 & 4 & 15 & 96 & 75 & 4.5 \\
B6 & 3 & 4 & 15 & 96 & 100 & 4.5 \\
\hline
\end{tabular}

Experimental programme is graphically represented in Figure 15. 


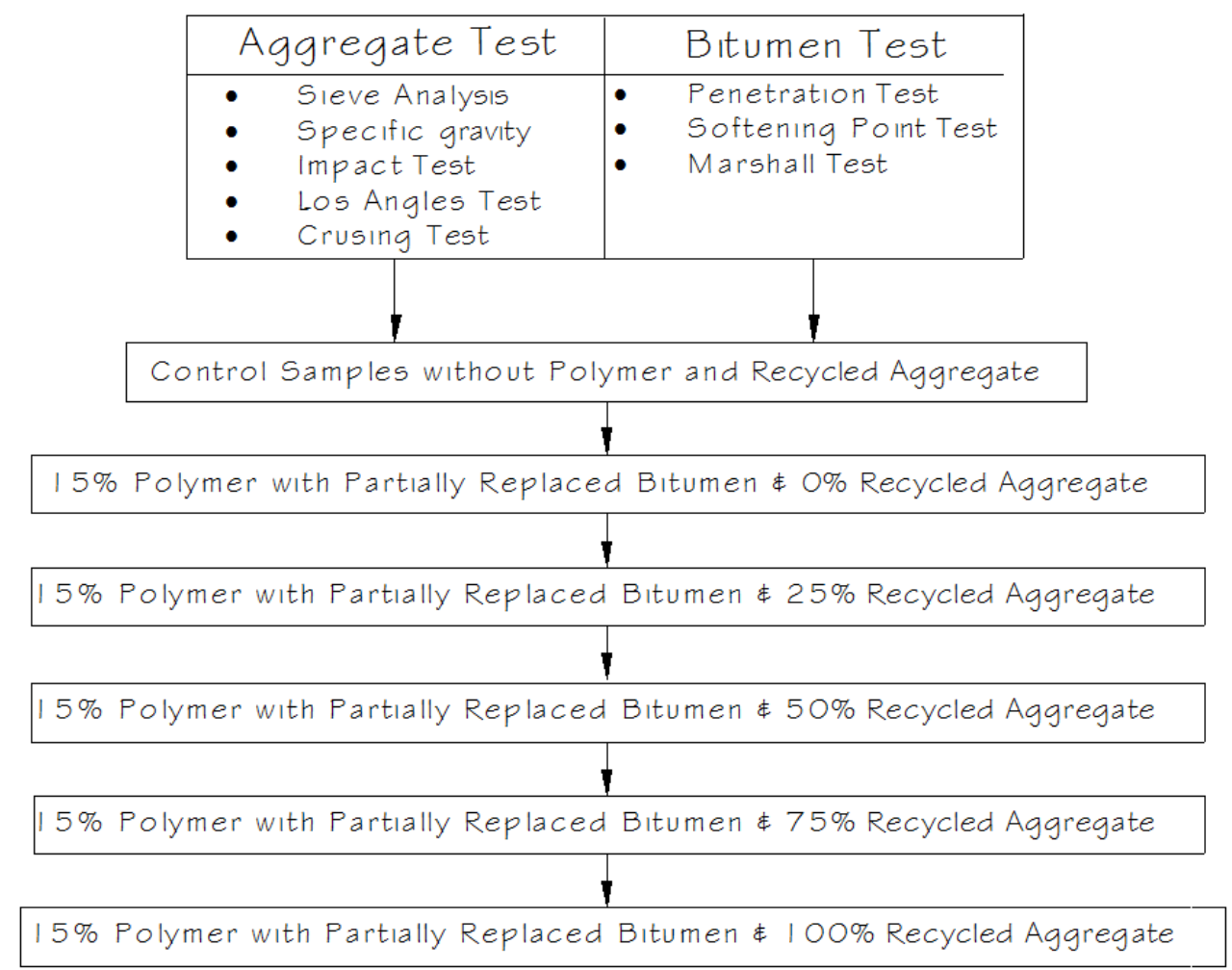

Figure 15. Experimental programme

Sieve analysis test results for normal and recycled coarse aggregate are presented in Tables 2 and 3.

Table 2. Sieve analysis for normal coarse aggregate

\begin{tabular}{ccccc}
\hline $\begin{array}{c}\text { Sieve Size } \\
(\mathbf{1})\end{array}$ & $\begin{array}{c}\text { Mass Retrained (g) } \\
(\mathbf{2})\end{array}$ & $\begin{array}{c}\text { Cumulative Mass } \\
\text { Retrained (g) } \\
\mathbf{( 3 )}\end{array}$ & $\begin{array}{c}\text { \% of Cumulative } \\
\text { Mass Retrain } \\
\mathbf{( 4 )}\end{array}$ & $\begin{array}{c}\text { \% of Passing } \\
\mathbf{( 5 )}\end{array}$ \\
\hline $25 \mathrm{~mm}$ & 0 & 0 & 0 & 100 \\
$20 \mathrm{~mm}$ & 32.2 & $0+32.2=32.2$ & 1.61 & 98.3 \\
$14 \mathrm{~mm}$ & 392.4 & $32+392.4=424.6$ & 21.23 & 78.77 \\
$10 \mathrm{~mm}$ & 1214.7 & 1639.3 & 81.9 & 18.1 \\
$6.3 \mathrm{~mm}$ & 348.6 & 1987.9 & 99.3 & 0.7 \\
$5 \mathrm{~mm}$ & 6.8 & 1994.7 & 99.7 & 0.3 \\
pan & 5.3 & 2000 & 100 & 0 \\
\hline FM $=\frac{\epsilon C U M}{100}=\frac{\epsilon(4)}{100}=\frac{403.74}{100}=4.04 \%$ & & & \\
\hline
\end{tabular}

Table 3. Sieve analysis for recycled coarse aggregate

\begin{tabular}{ccccc}
\hline $\begin{array}{c}\text { Sieve Size } \\
(\mathbf{1})\end{array}$ & $\begin{array}{c}\text { Mass of Aggregate } \\
\text { Retrained (g) } \\
(\mathbf{2})\end{array}$ & $\begin{array}{c}\text { Cumulative Mass of } \\
\text { Aggregate Retrained (g) } \\
(\mathbf{3})\end{array}$ & $\begin{array}{c}\text { \% of Aggregate } \\
\text { Cumulative Mass Retrain } \\
(\mathbf{4})\end{array}$ & $\begin{array}{c}\text { \% of Passing } \\
\mathbf{( 5 )}\end{array}$ \\
\hline $25 \mathrm{~mm}$ & 17.4 & 17.4 & 0.87 & 99.13 \\
$20 \mathrm{~mm}$ & 35.1 & 52.5 & 2.63 & 97.37 \\
$14 \mathrm{~mm}$ & 223.3 & 275.8 & 13.79 & 86.21 \\
$10 \mathrm{~mm}$ & 1404.7 & 1680.5 & 84.03 & 15.97 \\
$6.3 \mathrm{~mm}$ & 298.6 & 1979.1 & 98.96 & 1.04 \\
$5 \mathrm{~mm}$ & 12.1 & 1991.2 & 99.56 & 0.44 \\
pan & 8.8 & 2000 & 100 & 0 \\
\hline \multirow{2}{*}{$\mathrm{FM}=\frac{\epsilon \text { CUM } \%}{100}=\frac{\epsilon(4)}{100}=\frac{399.84}{100}=4 \%$} & & & \\
\hline
\end{tabular}




\subsection{Sample 1, Reference / Control Sample}

Marshall Test samples are to be prepare without partially replacement of polymers nor recycled aggregate as per the percentages following;

$\%$ of bitumen content $=4 \%$

$\%$ of aggregate $\quad=96 \%$

Weight of aggregate $=1296 \mathrm{~g}$

Weight of bitumen $=54 \mathrm{~g}$

Sample total weight $=1350 \mathrm{~g}$

Sample 1 control sample mix design is shown in Table 4 and preparation is shown in Figures 16 to 19.

Table 4. Sample 1 mix design

\begin{tabular}{cccccc}
\hline Sieves & $\%$ & $\begin{array}{c}\text { Weight of each } \\
\text { sieve }(\mathbf{g})\end{array}$ & $\begin{array}{c}\text { Normal aggregate } \\
(\mathbf{g})\end{array}$ & $\begin{array}{c}\text { Recycled aggregate } \\
(\mathbf{g})\end{array}$ & $\begin{array}{c}\text { Cum. Wt. Sieve } \\
(\mathbf{g})\end{array}$ \\
\hline $37.5-25$ & 0 & 0 & 0 & 0 & 0 \\
$25-12$ & 10 & 129.6 & 129.6 & 0 & 129.6 \\
$12-6$ & 32 & 414.72 & 414.72 & 0 & 544.32 \\
$6-3$ & 22 & 285.12 & 285.12 & 0 & 829.44 \\
$3-0$ & 31.5 & 408.24 & 408.24 & 0 & 1237.68 \\
Filler & 4.5 & & 58.32 & & 1296 \\
Bitumen & 4 & & 54 & & 1350 \\
\hline
\end{tabular}

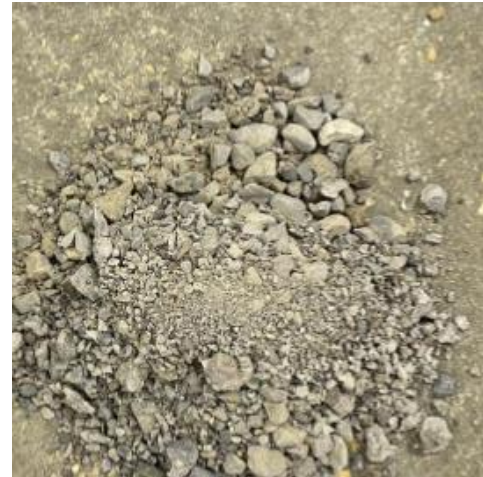

Figure 16. Preparation of Batch-1 Sample

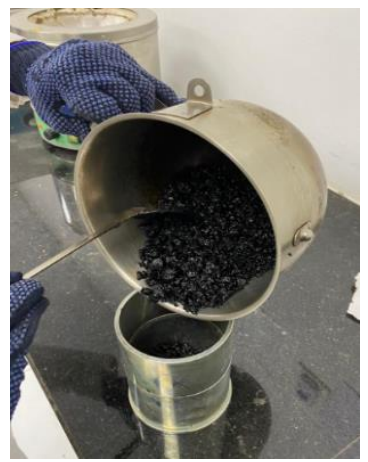

Figure 18. Puttting the hot mix sample in the mould

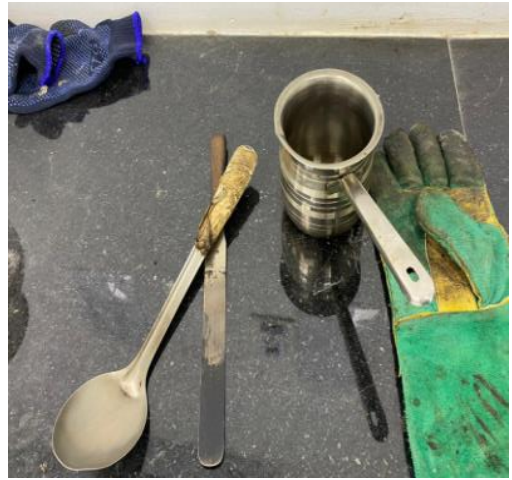

Figure 17. Some equipment used to prepare the asphalt mix

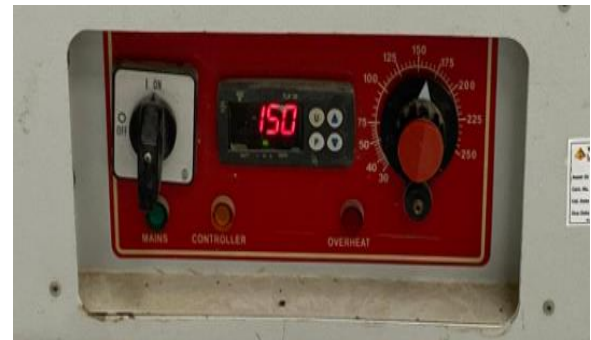

Figure 19. Putting the mould in the drying oven at $155^{\circ} \mathrm{C}$

In Marshal Test was conducted for sample 1 to 6. 


\section{Result and Discussion}

\subsection{Penetration Test without Plastic}

Penetration test without polymer is shown in Table 5 and with polymer $15 \%$ is shown in Table 6 . It is also shown in Figure 20

Table 5. Penetration test without polymer

\begin{tabular}{cc}
\hline Trial number & Penetration Value mm \\
\hline 1 & 64 \\
2 & 64 \\
3 & 63 \\
\hline Average & 63.7 \\
\hline
\end{tabular}

Table 6. Penetration test with adding $15 \%$ polymer

\begin{tabular}{cc}
\hline Trial number & Penetration Value $\mathbf{~ m m}$ \\
\hline 1 & 58 \\
2 & 57 \\
3 & 59 \\
\hline Average & 58
\end{tabular}

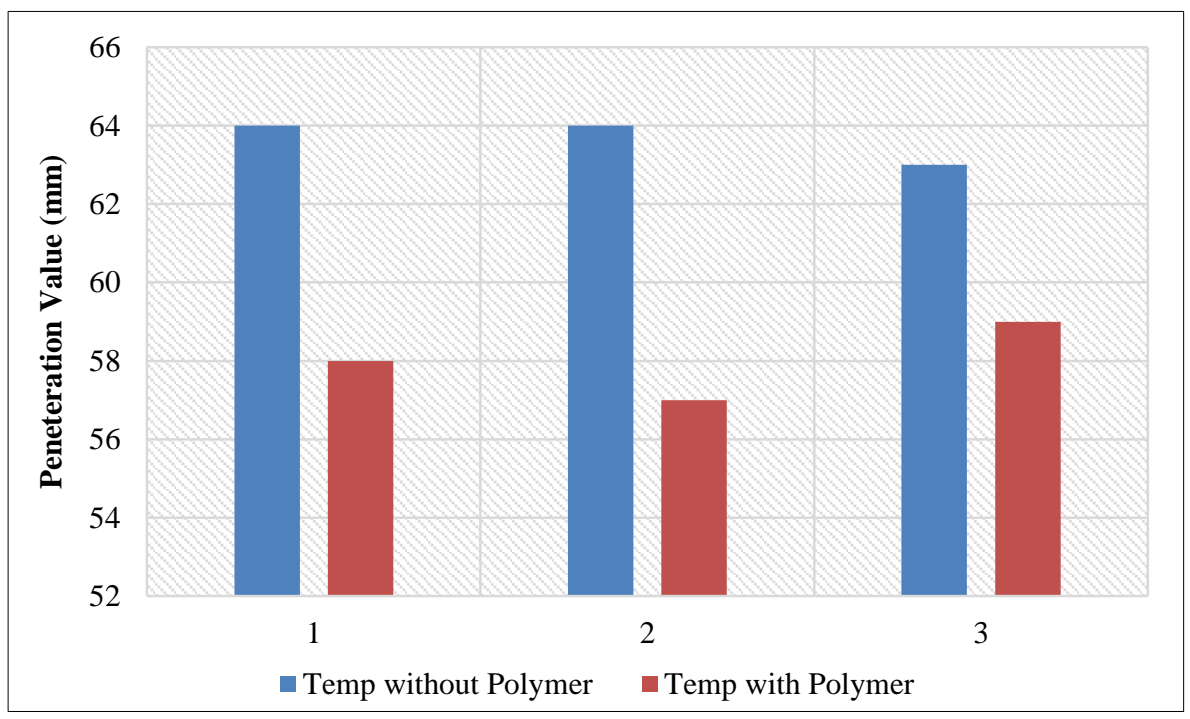

Figure 20. Penetration test results

The property of hardness for the bitumen and different materials can be found by conducting a penetration test. The hardness from its definition is the resistance of the material to penetration. By considering $15 \%$ partially replaced polymer from bitumen, the average value of penetration was found to be $58 \mathrm{~mm}$ and without replacement of polymer in the bitumen, the average penetration value was found to be $63.7 \mathrm{~mm}$. There average range of penetration value should fall within the range $(60-70 \mathrm{~mm})$ as specified by the grade of bitumen which is $60 / 70$. The values extracted from the experiment is reliable since it is very close to the range of $60-70 \mathrm{~mm}$.

\subsection{Marshall Test Result}

In Table 7 represented the average results of batch-1, batch-2, batch-3, batch-4, batch-5 and batch- 6 .

Table 7. Average results for all the batches

\begin{tabular}{|c|c|c|c|c|c|c|c|c|c|c|}
\hline $\begin{array}{c}\text { Batch } \\
\text { Number }\end{array}$ & $\begin{array}{c}\text { Plastic } \\
\text { Content } \%\end{array}$ & $\begin{array}{c}\text { Recycled } \\
\text { aggregate \% }\end{array}$ & $\begin{array}{c}\text { Bitumen } \\
\text { content \% }\end{array}$ & $\begin{array}{c}\text { Mass in } \\
\text { Air } \\
(\mathrm{gm})\end{array}$ & $\begin{array}{c}\text { Mass in } \\
\text { water (gm) }\end{array}$ & $\begin{array}{c}\text { SSD } \\
(\mathrm{g})\end{array}$ & $\begin{array}{c}\text { Volume } \\
\text { cc }\end{array}$ & $\begin{array}{l}\text { Bulk Sp. Gr } \\
\text { Gm/cc }\end{array}$ & $\begin{array}{l}\text { Max Load } \\
\text { at failure }\end{array}$ & $\begin{array}{c}\text { Flow Mm } \\
\text { or } 0.25 \mathrm{~mm}\end{array}$ \\
\hline 1 & 0 & 0 & 4 & 1362.8 & 766.6 & 1370.45 & 503.85 & 2.705 & 5.325 & 3.05 \\
\hline 3 & 15 & 25 & 4 & 1355.55 & 764.25 & 1364.1 & 503.8 & 2.685 & 7.73 & 1.485 \\
\hline 4 & 15 & 50 & 4 & 1356.7 & 766.8 & 1364.5 & 504.3 & 2.69 & 8.58 & 2.13 \\
\hline 5 & 15 & 75 & 4 & 1368.7 & 775.75 & 1377.85 & 504.95 & 2.71 & 12.215 & 3.375 \\
\hline 6 & 15 & 100 & 4 & 1351.4 & 751.65 & 1363.65 & 503.75 & 2.685 & 11.045 & 3.23 \\
\hline
\end{tabular}


The mass of air value is shown in Figure 21. In the first batch when there is no replacement by polymer nor RCA, the sample mass in the air was found to be $1362.8 \mathrm{gm}$. In the second batch when the bitumen was partially replaced by $15 \%$ polymer, the sample mass in the air was found to be $1376.8 \mathrm{gm}$. In the third batch when the bitumen was partially replaced by $15 \%$ polymer and the normal coarse aggregate was partially replaced by $25 \%$ RCA, the sample mass in the air was found to be 1355.55 gm which is the lowest mass. In the fourth batch when the bitumen was partially replaced by $15 \%$ polymer and the normal coarse aggregate was partially replaced by $50 \%$ RCA, the sample mass in the air was found to be $1356.7 \mathrm{gm}$. In the fifth batch when the bitumen was partially replaced by $15 \%$ polymer and the normal coarse aggregate was partially replaced by $75 \%$ RCA, the sample mass in the air is maximum and found to be $1368.7 \mathrm{gm}$. In the sixth batch when the bitumen was partially replaced by $15 \%$ polymer and the normal coarse aggregate was replaced by $100 \%$ RCA, the sample mass in the air was found to be 1351.4.

Among the 6 batches, the results show that when the bitumen was partially replaced by $15 \%$ polymer and the normal coarse aggregate was partially replaced by $75 \%$ recycled coarse aggregate (batch 5) gives better results.

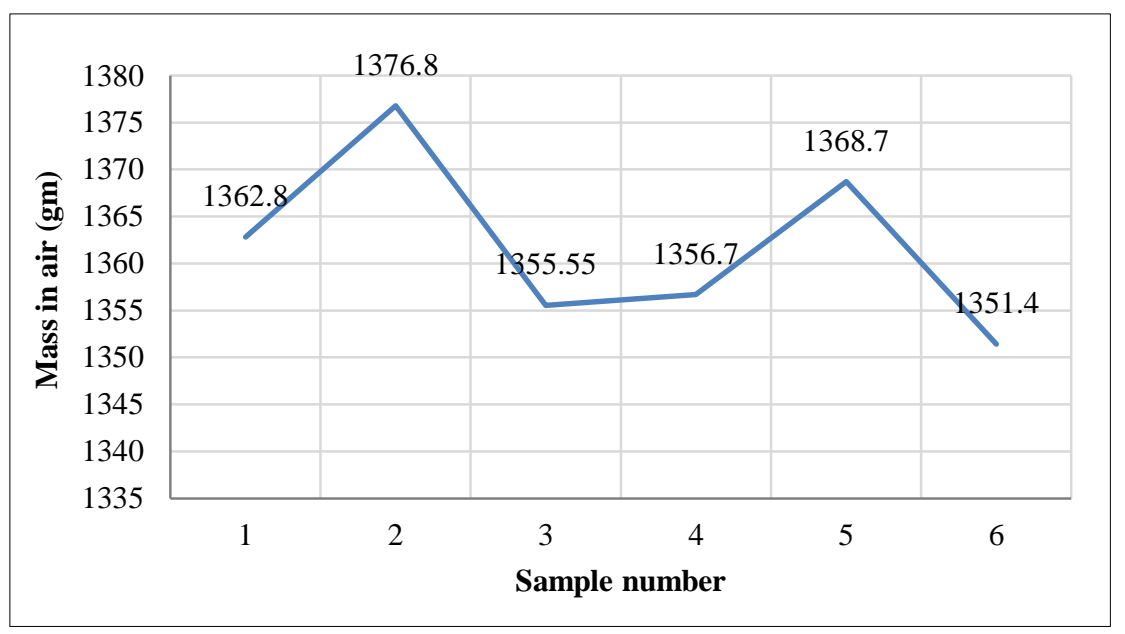

Figure 21. Mass in air values for six batches

The mass of water vs. sample number is shown in Figure 22. In the first batch when there is no replacement by polymer nor RCA, the sample mass in water was found to be $766.6 \mathrm{gm}$. In the second batch when the bitumen was partially replaced by $15 \%$ polymer, the sample mass in water was found to be $777.35 \mathrm{gm}$. In the third batch when the bitumen was partially replaced by $15 \%$ polymer and the normal coarse aggregate was partially replaced by $25 \%$ RCA, the sample mass in water was found to be $764.25 \mathrm{gm}$. In the fourth sample when the bitumen was partially replaced by $15 \%$ polymer and the normal coarse aggregate was partially replaced by $50 \%$ RCA, the sample mass in water was found to be $755.8 \mathrm{gm}$. In the fifth batch when the bitumen was partially replaced by $15 \%$ polymer and the normal coarse aggregate was partially replaced by $75 \%$ RCA, the sample mass in water is maximum and found to be 775.75 gm. In the sixth batch when the bitumen was partially replaced by $15 \%$ polymer and the normal coarse aggregate was replaced by $100 \%$ RCA, the sample mass in water was found to be $751.65 \mathrm{gm}$ which is the lowest mass. The results show that when the bitumen was partially replaced by $15 \%$ polymer and the normal coarse aggregate was partially replaced by $75 \%$ recycled coarse aggregate (batch 5 ) gives better results compared to other batches.

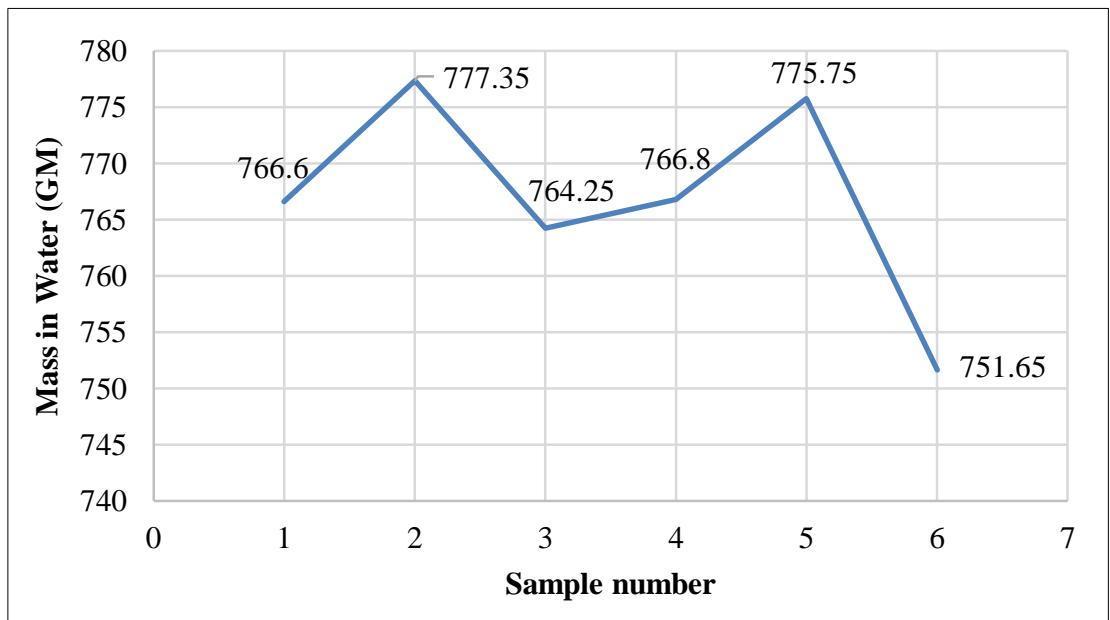

Figure 22. Mass in water values for six batches 
The saturated surface dry (SSD) vs. sample number is shown in Figure 23. In the first batch when there is no replacement by polymer nor RCA, SSD was found to be $1370.45 \mathrm{gm}$. In the second batch when the bitumen was partially replaced by $15 \%$ polymer, the sample's SSD was found to be $1380.2 \mathrm{gm}$. In the third batch when the bitumen was partially replaced by $15 \%$ polymer and the normal coarse aggregate was partially replaced by $25 \%$ RCA, SSD was found to be $1364.1 \mathrm{gm}$. In the fourth batch when the bitumen was partially replaced by $15 \%$ polymer and the normal coarse aggregate was partially replaced by 50\% RCA, SSD was found to be $1364.5 \mathrm{gm}$. In the fifth batch when the bitumen was partially replaced by $15 \%$ polymer and the normal coarse aggregate was partially replaced by $75 \%$ RCA, SSD is maximum and found to be $1377.85 \mathrm{gm}$. In the sixth batch when the bitumen was partially replaced by $15 \%$ polymer and the normal coarse aggregate was replaced by $100 \%$ RCA, SSD was found to be 1363.65 gm which is the lowest mass. The results show that when the bitumen was partially replaced by $15 \%$ polymer and the normal coarse aggregate was partially replaced by $75 \%$ recycled coarse aggregate (batch 5) shows better results.

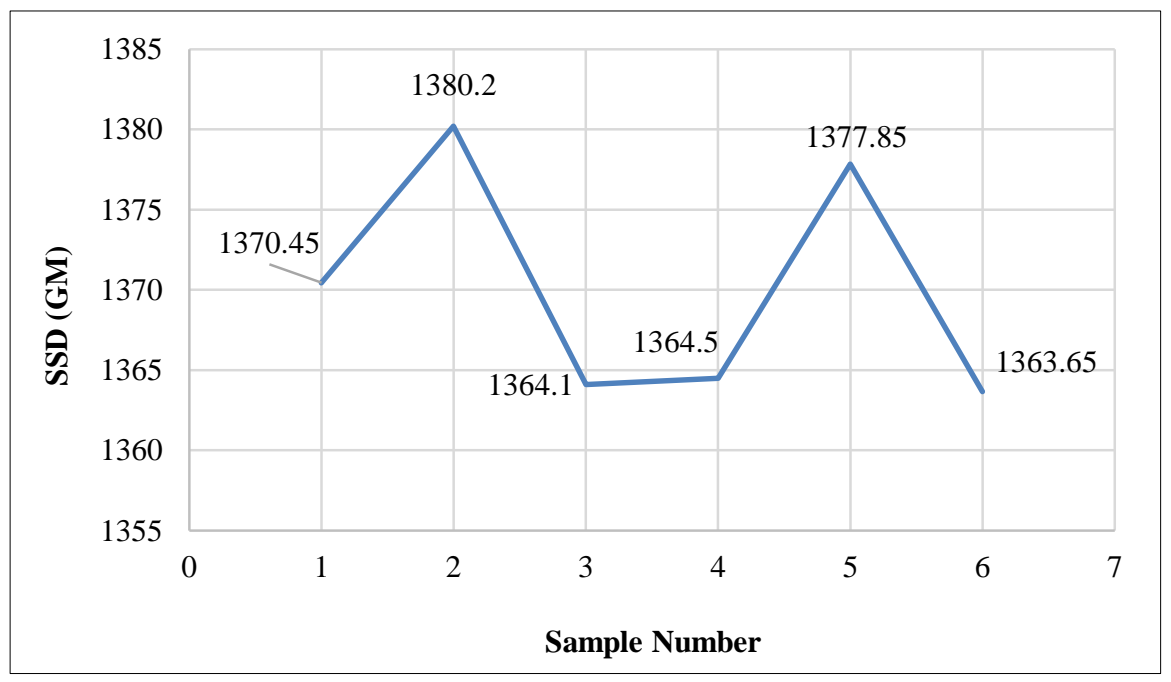

Figure 23. Saturated surface dry (SSD) values for six batches

The volume vs. batch number is shown in Figure 24. In the first batch when there is no replacement by polymer nor RCA, the volume was found to be $503.85 \mathrm{~cm}^{3}$.In the second sample when the bitumen was partially replaced by $15 \%$ polymer, the sample's volume was found to be $502.95 \mathrm{~cm}^{3}$. In the third batch when the bitumen was partially replaced by $15 \%$ polymer and the normal coarse aggregate was partially replaced by $25 \%$ RCA, the volume was found to be $503.8 \mathrm{~cm}^{3}$. In the fourth batch when the bitumen was partially replaced by $15 \%$ polymer and the normal coarse aggregate was partially replaced by $50 \%$ RCA, the volume was found to be $504.3 \mathrm{~cm}^{3}$. In the fifth batch when the bitumen was partially replaced by $15 \%$ polymer and the normal coarse aggregate was partially replaced by $75 \%$ RCA, the volume is maximum and found to be $504.95 \mathrm{~cm}^{3}$. In the sixth batch when the bitumen was partially replaced by $15 \%$ polymer and the normal coarse aggregate was replaced by $100 \%$ RCA, the volume was found to be $503.75 \mathrm{~cm}^{3}$ which is the lowest Volume. The results show that when the Bitumen was partially replaced by $15 \%$ polymer and the normal coarse aggregate was partially replaced by $75 \%$ recycled coarse aggregate (batch 5), better results were obtained.

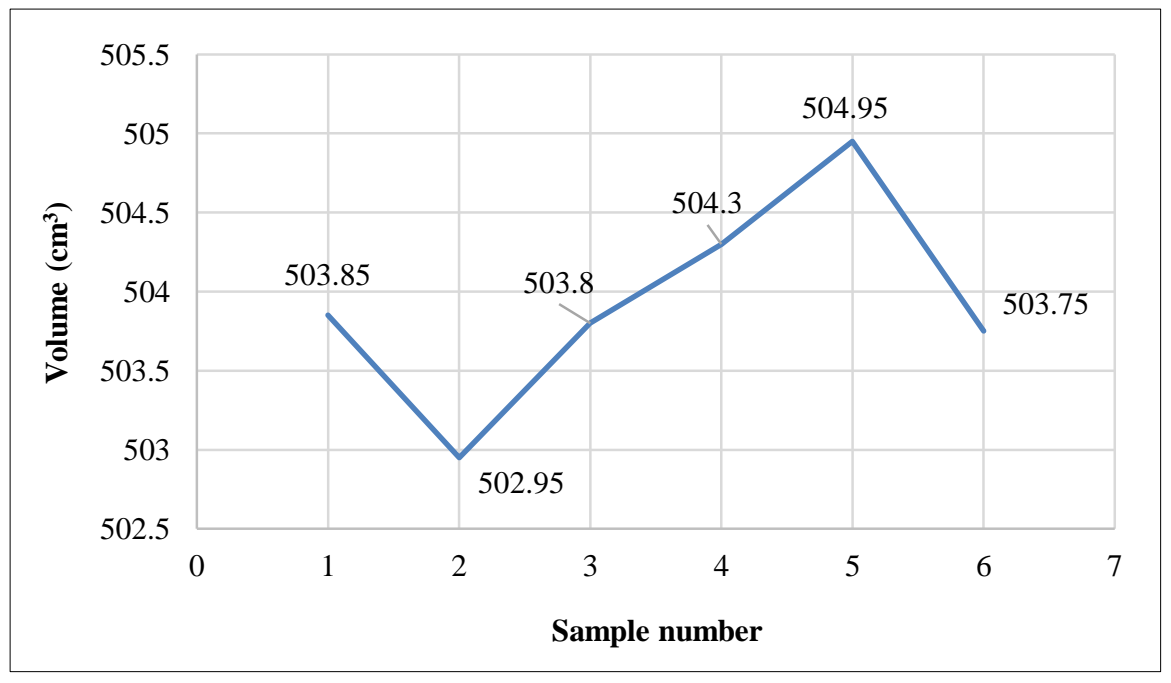

Figure 24. Volume for six sample 
The bulk specific gravity vs. batch Number is shown in Figure 25. In the first batch when there is no replacement by polymer nor RCA, the specific gravity was found to be 2.705 . In the second batch when the bitumen was partially replaced by $15 \%$ polymer, the sample's specific gravity was found to be 2.735 . In the third batch when the bitumen was partially replaced by $15 \%$ polymer and the normal coarse aggregate was partially replaced by $25 \%$ RCA, the specific gravity was found to be 2.685 . In the fourth batch when the bitumen was partially replaced by $15 \%$ polymer and the normal coarse aggregate was partially replaced by $50 \%$ RCA, the specific gravity was found to be 2.69 . In the fifth batch when the bitumen was partially replaced by $15 \%$ polymer and the normal coarse aggregate was partially replaced by $75 \%$ RCA, the specific gravity is maximum and found to be 2.71 . In the sixth batch when the bitumen was partially replaced by $15 \%$ polymer and the normal coarse aggregate was replaced by $100 \%$ RCA, the specific gravity was found to be 2.685 . The results show that when the bitumen was partially replaced by $15 \%$ polymer and the normal coarse aggregate was partially replaced by $75 \%$ recycled coarse aggregate (batch), good results were obtained.

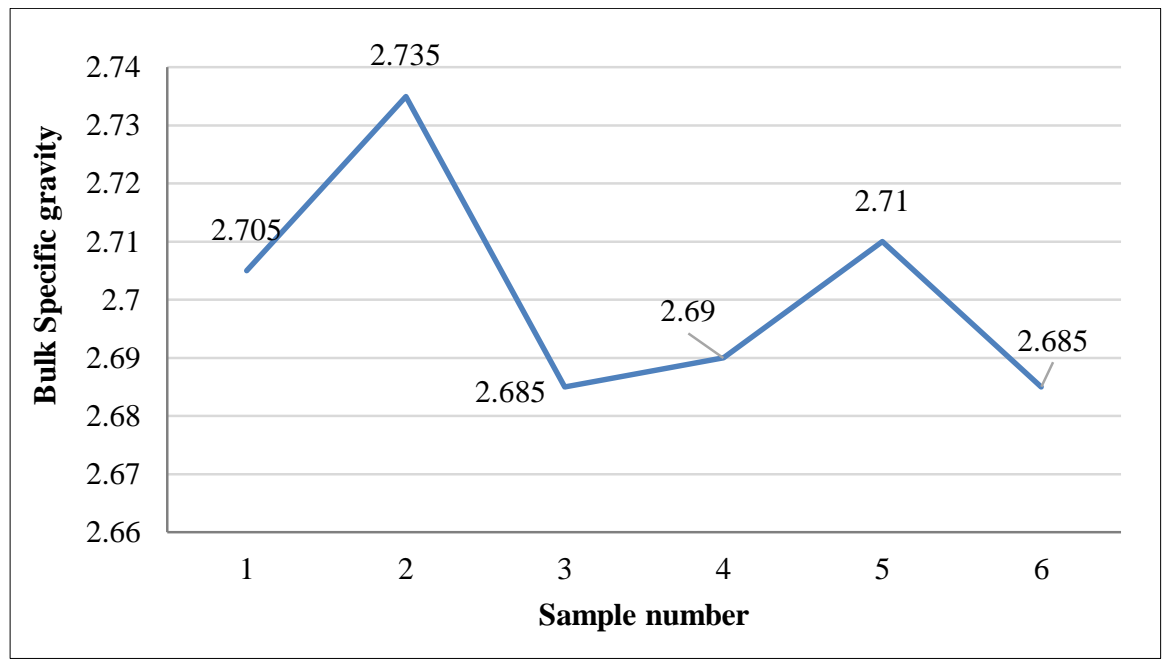

Figure 25. Bulk specific gravity values for six mixes

The maximum load at failure vs. batch number is shown in Figure 26. In the first batch when there is no replacement by polymer nor RCA, the max load at failure was found to be $5.325 \mathrm{kN}$. In the second batch when the bitumen was partially replaced by $15 \%$ polymer, the sample's specific gravity was found to be $5.775 \mathrm{kN}$. In the third batch when the bitumen was partially replaced by $15 \%$ polymer and the normal coarse aggregate was partially replaced by $25 \% \mathrm{RCA}$, the specific gravity was found to be $7.73 \mathrm{kN}$. In the fourth batch when the bitumen was partially replaced by $15 \%$ polymer and the normal coarse aggregate was partially replaced by $50 \%$ RCA, the Specific gravity was found to be $8.58 \mathrm{kN}$. In the fifth batch when the bitumen was partially replaced by $15 \%$ polymer and the normal coarse aggregate was partially replaced by $75 \%$ RCA, the specific gravity is maximum and found to be 12.215 $\mathrm{kN}$. In the sixth batch when the bitumen was partially replaced by $15 \%$ polymer and the normal coarse aggregate was replaced by $100 \%$ RCA, the specific gravity was found to be $11.045 \mathrm{kN}$. The results show that when the Bitumen was partially replaced by $15 \%$ polymer and the normal coarse aggregate was partially replaced by $75 \%$ recycled coarse aggregate (batch 5), the best results were obtained.

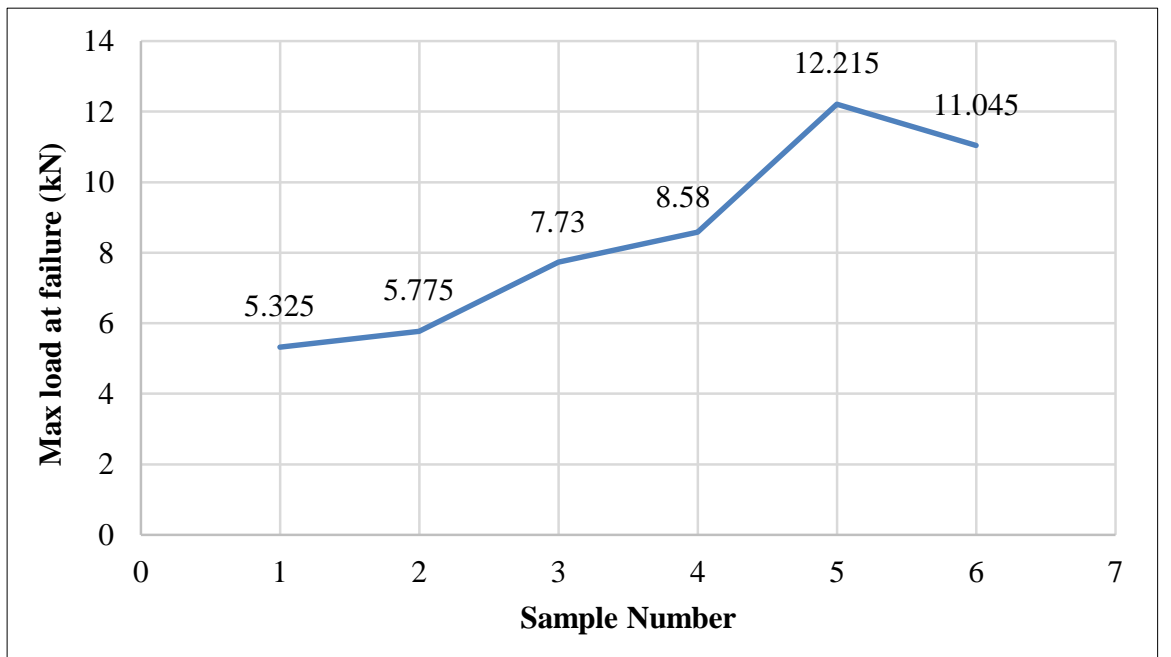

Figure 26. Maximum failure load for six samples 


\subsection{Eco-friendly Roads Feasibility Study}

The Eco-friendly roads are utilizing the recycled aggregates resulted from a demolished building in addition to the utilization of recycling polymers that are considered as non-degradable. However, the utilization of these will help in reducing the cost, in addition, to help the environment by reducing the accumulation of such negative effects. The question of whether the utilization of these inroads will improve the properties and enable the roads to function well will decide on the feasibility of such an approach. The answer to such a feasible question is the results obtained from the research work of this project. It has been proved by results of experimental work and conducting a reliable experiment to such mixture that properties are improved such as strength, penetration, hardness, toughness, waterproof, reduction of a number of voids, and moisture. Thus, the utilization of RCA and polymers in bitumen will definitely enable the roads to function better at low cost, achieve sustainability and reduce the negative impact on the environment.

\section{Conclusions}

In order to improve the quality of the road and its performance, recycled aggregate and partially polymer replacement are used together. The utilization of polymers within the previously mentioned mixture will improve the quality of roads in addition to that, it helps in decreasing the number of voids and the moisture content. The existence of polymers within roads has the advantage of being more durable by increasing the load that roads can withstand. As a result of this project, it can be easily noticed that adding polymers by $15 \%$ to road construction will lead to an increase in strength and performance. This utilization of recycled aggregate and polymers will help in attaining sustainability and reducing the negative effects on the environment by being considered a friendly environmental technique. The recycle aggregate and polymers utilization have proved that such techniques are feasible and accompanied with many advantages including cost reduction, improving properties like strength, increase mixture ability to be bent, and decreasing moisture content and porosity. The treatment of plastic waste material at a high temperature improves the bitumen's viscosity.

Based on the detailed experimental investigation the following conclusions are drawn:

- The Sieve Analysis test shows that the fineness modulus value for recycled coarse aggregate (RCA) and normal coarse aggregate (NCA) equals $4 \%$ and that both the aggregates are uniformly graded.

- The RCA and NCA specific gravity values are found to be 2.61 and 2.78, respectively, so that RCA is classified as a coarse-grained aggregate that can be used for road construction.

- The RCA and NCA impact values equal 9.3 and 3.62\%, respectively, which indicates that the Recycled Coarse Aggregate is exceptionally strong for road construction.

- The Los Angeles test results for RCA and NCA showed that the total abrasion equals 19.07 and 13.63\%, which are the acceptable limits.

- Penetration test results show that for cases with and without adding $15 \%$ polymers, the average values are found to be $63.7 \mathrm{~mm}$ (without polymers) and with polymers, the value is $58 \mathrm{~mm}$. This shows that higher penetration quality results indicate better reliability.

- The marshal test results show that batch 5 , which is $15 \%$ polymer with $75 \%$ recycled aggregate, gives better results in all aspects.

- Batch 5 gives better strength, higher water resistance, and better performance over a period of time when combined with the binder.

In addition to that, this will lead to improving traffic life as well as helping to protect the environment. The ecofriendly road using recycled coarse aggregate and recycled polymers will achieve sustainability, the target of all.

\section{Declarations}

\subsection{Author Contributions}

All authors contributed to the design and implementation of the research, to the analysis of the results, and to the writing of the manuscript. All authors read and approved the final manuscript.

\subsection{Data Availability Statement}

The data presented in this study are available on request from the corresponding author.

\subsection{Funding}

The authors received no financial support for the research, authorship, and/or publication of this article. 


\subsection{Institutional Review Board Statement}

Not applicable.

\subsection{Informed Consent Statement}

Not applicable.

\subsection{Declaration of Competing Interest}

The authors declares that there is no conflict of interests regarding the publication of this manuscript. In addition, the ethical issues, including plagiarism, informed consent, misconduct, data fabrication and/or falsification, double publication and/or submission, and redundancies have been completely observed by the authors.

\section{References}

[1] Priyanka, A. (2020). Analysis in the Application of Plastic Waste as a Constructive Material in Flexible Pavement. Turkish Journal of Computer and Mathematics Education (TURCOMAT), 12(7), 166-170.

[2] Qasrawi, H., \& Asi, I. (2016). Effect of bitumen grade on hot asphalt mixes properties prepared using recycled coarse concrete aggregate. Construction and Building Materials, 121, 18-24. doi:10.1016/j.conbuildmat.2016.05.101.

[3] Abdel Bary, E. M., Farag, R. K., Ragab, A. A., Abdel-monem, R. M., Abo-shanab Z. L., \& Saleh, A. M. M. (2019). Green asphalt construction with improved stability and dynamic mechanical properties. Polymer Bulletin, 77(4), $1729-1747$. doi:10.1007/s00289-019-02821-z.

[4] Appiah, J. K., Berko-Boateng, V. N., \& Tagbor, T. A. (2017). Use of waste plastic materials for road construction in Ghana. Case Studies in Construction Materials, 6, 1-7. doi:10.1016/j.cscm.2016.11.001.

[5] Umana, U. S., Ebong, M. S., \& Godwin, E. O. (2020). Biomass Production from Oil Palm and Its Value Chain. Journal of Human, Earth, and Future, 1(1), 30-38. doi:10.28991/HEF-2020-01-01-04.

[6] Anwar, M. I., Arifuzzaman, M., \& Rahman, M. M. (2020). Assessment of Environmental Impact and Energy Demand of Sulfur Modified Asphalt in Road Pavement. 2020 Second International Sustainability and Resilience Conference: Technology and Innovation in Building Designs (51154). doi:10.1109/ieeeconf51154.2020.9319983.

[7] Thakur, R. and Jaspreet Singh (2017). Study of Performance of Bituminous Concrete with Addition of Coir/Coconut Fiber. International Journal of Mechanical Engineering and Technology, 8(7), 1793-1799.

[8] Balaguera, A., Carvajal, G. I., Albertí, J., \& Fullana-i-Palmer, P. (2018). Life cycle assessment of road construction alternative materials: A literature review. Resources, Conservation and Recycling, 132, 37-48. doi:10.1016/j.resconrec.2018.01.003.

[9] Diez, J., Castro, D., Casado, R., Hubrich, C., Gaspar, L., \& Azpeitia, M. (2016). DURABROADS - Towards a more durable and resilient road pavement. Proceedings of 6th Eurasphalt \& Eurobitume Congress. doi:10.14311/ee.2016.424.

[10] Attaran Dovom, H., Mohammadzadeh Moghaddam, A., Karrabi, M., \& Shahnavaz, B. (2019). Improving the resistance to moisture damage of cold mix asphalt modified by eco-friendly Microbial Carbonate Precipitation (MCP). Construction and Building Materials, 213, 131-141. doi:10.1016/j.conbuildmat.2019.03.262.

[11] Radević, A., Đureković, A., Zakić, D., \& Mladenović, G. (2017). Effects of recycled concrete aggregate on stiffness and rutting resistance of asphalt concrete. Construction and Building Materials, 136, $386-393$. doi:10.1016/j.conbuildmat.2017.01.043.

[12] Sahu, A. K., \& Singh, R. K. (2016). Application of waste plastic materials in road construction. In 2nd International Seminar On-Utilization of Non-Conventional Energy Sources for Sustainable Development of Rural Areas ISNCESR 17th \& 18th March, University, Bhilai, Chhattisgarh, India.

[13] Boucherba, M., Kriker, A., \& Kebaili, N. (2017). The Valorisation of the Plastic Waste to the Rheological Characteristics of Bituminous Mixtures. AIP Publishing LLC. doi:10.1063/1.4976244.

[14] El-Tahan, D., Gabr, A., El-Badawy, S., \& Shetawy, M. (2018). Evaluation of recycled concrete aggregate in asphalt mixes. Innovative Infrastructure Solutions, 3(1). doi:10.1007/s41062-018-0126-7.

[15] Shanbara, H. K., Ruddock, F., \& Atherton, W. (2018). Stresses and strains distribution of a developed cold bituminous emulsion mixture using finite element analysis. Science and Technology behind Nanoemulsions, IntechOpen. doi:10.5772/intechopen.74221.

[16] Vasudevan, R. N. S. K., Velkennedy, R., Sekar, A. R. C., \& Sundarakannan, B. (2010). Utilization of waste polymers for flexible pavement and easy disposal of waste polymers. International Journal of Pavement Research and Technology, 3(1), 3442. 
[17] Shanbara, H. K., Shubbar, A., Ruddock, F., \& Atherton, W. (2019). Characterizing the Rutting Behaviour of Reinforced Cold Mix Asphalt with Natural and Synthetic Fibres Using Finite Element Analysis. Advances in Structural Engineering and Rehabilitation, 221-227. doi:10.1007/978-981-13-7615-3_20.

[18] Wang, H., Liu, X., Apostolidis, P., \& Scarpas, T. (2018). Review of warm mix rubberized asphalt concrete: Towards a sustainable paving technology. Journal of Cleaner Production, 177, 302-314. doi:10.1016/j.jclepro.2017.12.245.

[19] Tutu, K. A., \& Tuffour, Y. A. (2016). Warm-Mix Asphalt and Pavement Sustainability: A Review. Open Journal of Civil Engineering, 06(02), 84-93. doi:10.4236/ojce.2016.62008.

[20] Luhar, S., Cheng, T.-W., Nicolaides, D., Luhar, I., Panias, D., \& Sakkas, K. (2019). Valorisation of glass wastes for the development of geopolymer composites - Durability, thermal and microstructural properties: A review. Construction and Building Materials, 222, 673-687. doi:10.1016/j.conbuildmat.2019.06.169.

[21] Milad, A., Mohd Taib, A., G. F Ahmeda, A., Solla, M., \& Md Yusoff, N. I. (2020). A Review of the use of Reclaimed Asphalt Pavement for Road Paving Applications. Jurnal Teknologi, 82(3), 35-44. doi:10.11113/jt.v82.14320.

[22] Yu, H., Dai, W., Qian, G., Gong, X., Zhou, D., Li, X., \& Zhou, X. (2020). The NOx Degradation Performance of Nano-TiO2 Coating for Asphalt Pavement. Nanomaterials, 10(5), 897. doi:10.3390/nano10050897.

[23] Pouranian, M. R., \& Shishehbor, M. (2019). Sustainability Assessment of Green Asphalt Mixtures: A Review. Environments, 6(6), 73. doi:10.3390/environments6060073.

[24] Leng, C., Lu, G., Gao, J., Liu, P., Xie, X., \& Wang, D. (2019). Sustainable Green Pavement Using Bio-Based Polyurethane Binder in Tunnel. Materials, 12(12), 1990. doi:10.3390/ma12121990.

[25] Campos Teixeira, A. H., Soares Junior, P. R. R., Silva, T. H., Barreto, R. R., \& Silva Bezerra, A. C. da. (2020). Low-Carbon Concrete Based on Binary Biomass Ash-Silica Fume Binder to Produce Eco-Friendly Paving Blocks. Materials, $13(7), 1534$. doi:10.3390/ma13071534.

[26] Vandewalle, D., Antunes, V., Neves, J., \& Freire, A. C. (2020). Assessment of Eco-Friendly Pavement Construction and Maintenance Using Multi-Recycled RAP Mixtures. Recycling, 5(3), 17. doi:10.3390/recycling5030017.

[27] Wang, Cheng, Chen, Tan, Lv, \& Bai. (2019). Study on the Performances of Waste Crumb Rubber Modified Asphalt Mixture with Eco-Friendly Diatomite and Basalt Fiber. Sustainability, 11(19), 5282. doi:10.3390/su11195282.

[28] BS 812-2., (1995). Testing Aggregates. Methods for determination of density. British Standard, London, United Kingdom.

[29] BS EN 1097-2, (1998). Tests for Mechanical and Physical Properties of Aggregates. Methods for the Determination of Resistance to Fragmentation. British Standard, London, United Kingdom.

[30] BS EN 12697-34, (2012). Bituminous Mixtures. Test Methods for Hot Mix Asphalt. Marshall Test. British Standard, London, United Kingdom.

[31] BS EN 1426, (2007). Bitumen and Bituminous Binders. Determination of needle Penetration. British Standard, London, United Kingdom.

[32] BS EN 812-112, (1990). Testing aggregates. Method for determination of aggregate impact value (AIV). British Standard, London, United Kingdom. 